\title{
Does Socio-demographic Factors Influence Women's Choice of Place of Delivery in Rural Areas of Tamilnadu State in India
}

\author{
Rejoice Puthuchira Ravi ${ }^{1, *}$, Ravishankar Athimulam Kulasekaran ${ }^{2}$ \\ ${ }^{1}$ Consultant, IRHD, Kottayam, Kerala, India \\ ${ }^{2}$ Department of Population Studies, Annamalai University, Tamilnadu, India \\ *Corresponding author: pr.rejoice@gmail.com
}

Received August 17, 2013; Revised October 17, 2013; Accepted April 15, 2014

\begin{abstract}
Every day, approximately 1000 women die from preventable causes related to pregnancy and childbirth. Of which, $99 \%$ of all maternal deaths occur in developing countries. The aim of this study was to assess the sociodemographic factors influence women's choice of place of delivery in rural areas of Thiruvarur district of Tamilnadu state in India. A community based cross-sectional study was conducted in 28 villages selected using multistage sampling technique for selecting 605 women in the age group of 15-24 years during July 2010-April 2011. Data analysis was by use of Statistical Package for Social Sciences version-17, with statistical significance set at p-value of 0.05 . The study reveals that education, age at marriage, birth order, standard of living index and exposure to mass media appeared strong influencing factors for the choice of place of delivery among women in rural areas. The result shows that $69 \%$ of home deliveries were monitored by Traditional Birth Attendants (TBAs/Dais). Bivariate analysis indicates that all women who had completed higher secondary education were preferred the health institution for their delivery whereas $18.8 \%$ of home deliveries have been taken place among illiterates. The proportion of home deliveries (7.3\%) was higher among women in households in the less standard of living index. Home deliveries were higher among women who were less exposed to mass media (7.1\%) than more exposed to mass media (1.6\%). Birth order was significantly influence on the place of delivery among women. First birth order deliveries were less likely to take place at home (2.5\%) than second (8.2\%) and third birth order deliveries (9.1\%). It concludes that family tradition and poor socioeconomic condition of the family appear to be the main reasons for choosing to deliver at home. It recommends that Government should be taken a comprehensive strategy to increase the availability, accessibility and affordability of delivery care services in rural areas. Public health strategies involving traditional birth attendants will be beneficial particularly rural/remote areas where their services are highly utilized.
\end{abstract}

Keywords: home delivery, institutional delivery, scheduled castes, standard of living index, young women

Cite This Article: Rejoice Puthuchira Ravi, and Ravishankar Athimulam Kulasekaran, "Does Sociodemographic Factors Influence Women's Choice of Place of Delivery in Rural Areas of Tamilnadu State in India.” American Journal of Public Health Research, vol. 2, no. 3 (2014): 75-80. doi: 10.12691/ajphr-2-3-2.

\section{Introduction}

Home deliveries by traditional birth attendants (TBAs/Dais) are a cultural norm in rural areas of India. This is true both for rural areas as well as the urban slums. It's a common traditional belief that childbirth is a natural process which does not require any medical attention and should be conducted at home by the family 'Dai' who is a well-known and trusted figure for the family, is easily available and is not very expensive [1]. This attitude coupled with poverty, illiteracy and ignorance regarding complications of delivery, is responsible for the majority of women preferring to deliver at home in India.

The place of delivery is an important determinant for reducing the risk of infant and maternal death. Every day, approximately 1000 women die from preventable causes related to pregnancy and childbirth. Of which, $99 \%$ of all maternal deaths occur in developing countries. Maternal mortality is higher in rural areas and among poorer and less educated communities [2]. A significant proportion of mothers in developing countries still deliver at home unattended by skilled health workers [3,4]. In diverse contexts, individual factors including maternal age, parity, education and marital status, household factors including family size, household wealth, and community factors including socioeconomic status, community health infrastructure, region, rural/urban residence, available health facilities, and distance to health facilities determine place of delivery and these factors interact in diverse ways in each context to determine place of delivery $[5,6]$.

Maternal deaths are associated with inadequate medical care at the time of delivery. Several factors have been identified as barriers to access to skilled care by women in developing countries; include unavailability of the services, inadequate number of skilled personnel and 
geographical inaccessibility [7]. There are a number of socioeconomic and cultural factors that act as barriers to women's use of health services, the high cost of services has been identified as a major barrier facing rural women in seeking and using these life-saving services in many developing countries including China $[8,9,10]$.

In high income countries, 99\% of deliveries are conducted by skilled attendants compared to $59 \%$ in low income countries where over $90 \%$ of maternal death occurs [11]. According to the World Health Organization (WHO), cited by Letamo at al [12], 60 million deliveries take place annually worldwide where the woman is cared for by either a family member, an untrained traditional birth attendant, or no one at all. Increasing the proportion of women cared for in health facilities and by skilled health providers during pregnancy and childbirth is critically important for improving the health of mothers and newborns [13]. The main strategy to achieve the fifth Millennium Development Goal (MDG), which aims to improve maternal health, is to ensure that $90 \%$ of all births are attended by a skilled attendant in 2015 [11].

In developing countries, most women deliver at home for some reasons. The identified reasons for non utilization of obstetric services include: financial constraints, lack of awareness of maternity waiting homes, no perceived need for such services, preference for home delivery because it is much less expensive and etc [14]. Recent demographic and health survey (DHS) data from more than 50 developing countries shows that women with the limited education, knowledge of health services are less likely to use basic health services such as immunization, maternal care and family planning [15]. The determinants of maternal mortality includes the health and reproductive behaviour of the women, her health status, access to health services as well as her socioeconomic stats. It is important to identify the factors which lead to either home or hospital delivery [16].

\subsection{A Profile of Scheduled Castes Population in India}

The Indian caste system is a highly complex institution, though social institutions resembling caste in one respect or another are not difficult to find elsewhere, but caste is an exclusively Indian phenomenon. At presents, the scheduled castes in India constitute around $16.8 \%$ of the total population. Almost one-third of them live below poverty line and do not have access even to the basic needs like food, clothing, and shelter and constitute major part of our labour force and are generally engaged in petty occupations like agriculture labour, construction work, hawking and other low grade jobs [17]. There is a general consensus that the health status of the scheduled castes population is very poor and worst [18]. Under this circumstance, the present study made an attempt to assess the socio-demographic factors influence women's choice of place of delivery in rural areas of Thiruvarur district of Tamilnadu state in India.

\section{Materials and Methods}

\subsection{Study Area}

According to 2001 census, Thiruvarur district was the highest Scheduled Castes populated district and also backward district in Tamilnadu state. All women were living with their husbands and had given at least one birth one year prior to the survey.

\subsection{Study Design}

A community based cross-sectional study was conducted in 28 villages selected using multistage sampling technique for selecting 605 women in the age group of 15-24 years during July 2010-April 2011.

\subsection{Selection of the Blocks}

Thiruvarur district had totally ten blocks, which comprise 573 revenue villages. In the first stage, five blocks were selected which represent the geographical distribution of the study district. The selected blocks were Nannilam from north, Thiruvarur from east, Tiruturaipundi from south, Valangaiman from west and Mannargudi from central part of the study district.

\subsection{Selection of the Villages}

There were 352 revenue villages in these selected five blocks. In the second stage, all the villages which had 50 percent of scheduled castes population were selected. I.e. 87 villages were selected. For covering entire block, one third of the villages (5/6 villages) were selected from each block by simple random sampling method. Thus, 28 villages were selected for the research purpose.

\subsection{Selection of the Respondents}

In the third stage, house listing operation was carried out prior to the data collection to provide the necessary frame for selecting the households for the study. Totally 6376 houses were listed in all the five blocks. Identification of eligible young married women (15-24 years) in each household was the next step in the research. There were 1164 households with the target population (39 households had two couples). Totally 1203 women in the age group of 15-24 were identified.

Systematic random sampling technique was applied for selecting 21/22 respondents from each village. In order to take care of non-response due to various reasons, an extra $10 \%$ of respondents were included in the sample. i.e. 661 respondents were selected for the interview. Totally, 605 respondents were completed the interview and 32 respondents declined to participate interview. The response rate of the research study was $91.5 \%$.

\subsection{Data Collection Tools}

The respondents were assessed using a structured interviewer administered questionnaire which was pretested in Chidambaram Taluk near Annamalai University, about $102 \mathrm{~km}$ away from Thiruvarur district.

\subsection{Data Analysis}

Results were summarized and presented as frequencies and percentages and also Chi-square test was used for assessing the statistical significance at p-value. 


\subsection{Ethical Approval}

The syndicate review board at Annamalai University, Tamilnadu state, India has approved the research entitled "Reproductive and Sexual Health status of Scheduled Castes Youth in Thiruvarur district, Tamilnadu, India” for the degree of Doctor of Philosophy (Ph D) in Population Studies with effect from July 2012.

\subsection{Map of Thiruvarur District (Study Area)}

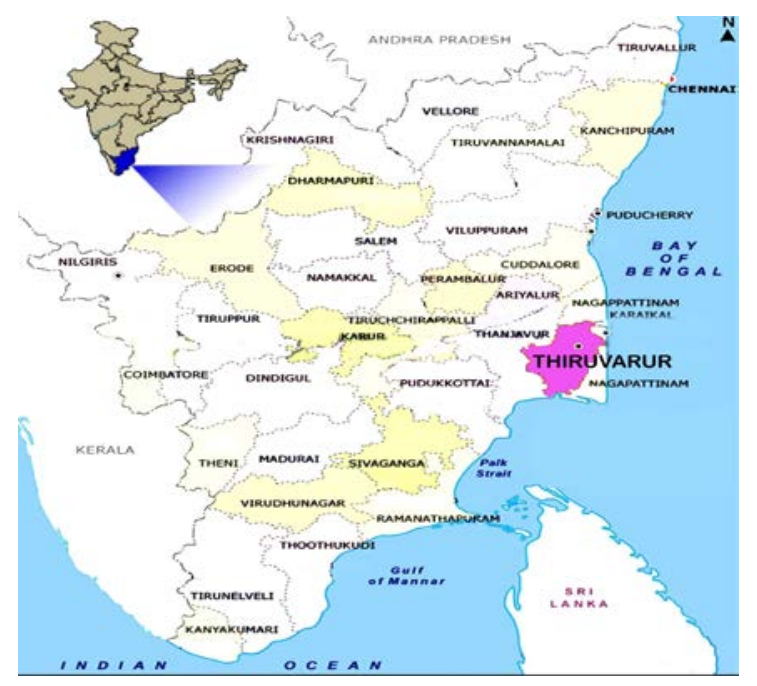

2.10. Study Settings

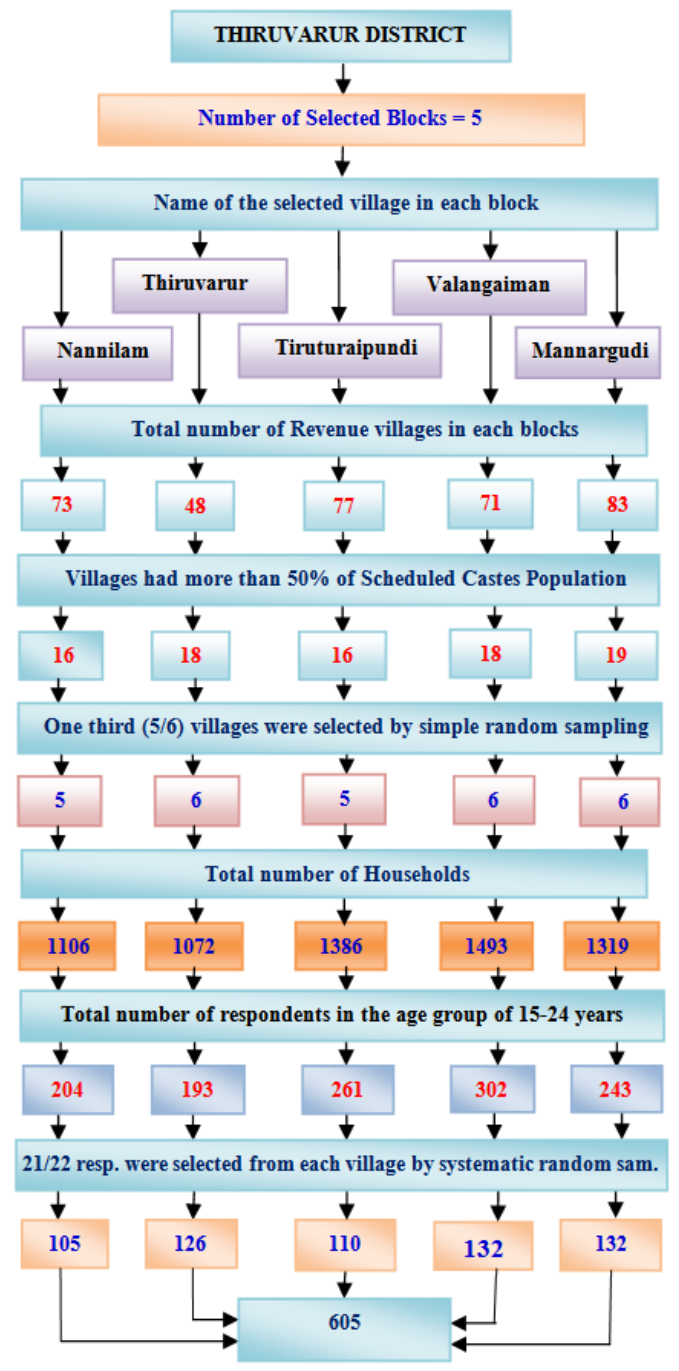

\section{Results}

\subsection{Place of Delivery}

All the women who participated in this research study were asked their place of delivery and the result are tabulated. The (Table 1 ) reveals that $4.8 \%$ of the deliveries took place at home among scheduled castes (SC) communities and the remaining $95.2 \%$ of the deliveries were taken place at institutions. Among the institutional deliveries, less than half of deliveries took place at government hospitals (47.6\%) and about 28.4\% child deliveries took place at primary health centers and another $18.5 \%$ of the children were born at the community health centers. The result reveals that only $0.7 \%$ of deliveries were took place at Private hospitals.

Table 1. Percentage distribution of women by Place of delivery

\begin{tabular}{|c|c|c|}
\hline Place of delivery & Frequency & Percentage \\
\hline Home & 29 & 4.8 \\
\hline Primary Health Centre & 172 & 28.4 \\
\hline Community Health centre & 112 & 18.5 \\
\hline Government Hospital & 288 & 47.6 \\
\hline Private hospital & 4 & 0.7 \\
\hline Total & 605 & 100.0 \\
\hline
\end{tabular}

\subsection{Assistance while Delivery}

The (Table 2) discloses that $69 \%$ of home deliveries were monitored by traditional birth attendants (TBAs/Dais) and the remaining deliveries were attended by village health nurse (31\%). With regard to primary health centers, more than three-fourth of the child deliveries were conducted by nurses (76.2\%) whereas only $23.8 \%$ of the child deliveries were attended by doctors. More than half of child deliveries were monitored by doctors (51.8\%) at community health centers. Overwhelming majority of the child deliveries were monitored by doctors (90.3\%) at Government hospitals.

Table 2. Percentage distribution of women by Assistance while delivery

\begin{tabular}{|c|c|c|}
\hline Assistance while delivery & Frequency & Percentage \\
\hline \multicolumn{3}{|c|}{ At home } \\
\hline TBA/Dais & 20 & 69.0 \\
\hline Village Health Nurse & 9 & 31.0 \\
\hline Total & 29 & 100.0 \\
\hline \multicolumn{3}{|c|}{ Primary Health Centers } \\
\hline Nurse & 131 & 76.2 \\
\hline Doctor & 41 & 23.8 \\
\hline Total & 172 & 100.0 \\
\hline \multicolumn{3}{|c|}{ Community Health Centers } \\
\hline Nurse & 54 & 48.2 \\
\hline Doctor & 58 & 51.8 \\
\hline Total & 112 & 100.0 \\
\hline \multicolumn{3}{|c|}{ Government Hospitals } \\
\hline Nurse & 28 & 9.7 \\
\hline Doctor & 260 & 90.3 \\
\hline Total & 288 & 100.0 \\
\hline
\end{tabular}

\subsection{Reasons for not Delivering at Institution}

The (Table 3) presents the percentage distribution of women according to main reasons for not delivering at institution. In the study area, around $79.3 \%$ of women reported that they had better care at home and another $69 \%$ stated that the Traditional Birth Attendants 
(TBAs/Dais) were available in their area. More than half of women reported that their family members did not allow them to visit the health facility for child delivery (55.2\%). It is also observed that $31 \%$ of women stated that the transportation facility was not available to reach the health centre. More than one-fourth of women stated that they had no time to visit the health institution for delivery (27.6\%).

Table 3. Percentage distribution of women by Reasons for not delivering at institution (Multiple responses)

\begin{tabular}{|c|c|c|}
\hline Reasons for not delivering at institution & Frequency & Percentage \\
\hline Family members did not allow & 16 & 55.2 \\
\hline Lack of time to health centre & 8 & 27.6 \\
\hline Transportation was not available & 9 & 31.0 \\
\hline Trained Dai available & 20 & 69.0 \\
\hline Better care at home & 23 & 79.3 \\
\hline Total & 29 & 100.0 \\
\hline \multicolumn{2}{|l}{}
\end{tabular}

\subsection{Place of Delivery by Socio-demographic Characteristics}

Table 4. Percentage distribution of women by Place of delivery according to their socio-demographic characteristics

\begin{tabular}{|c|c|c|c|c|c|}
\hline \multirow{2}{*}{$\begin{array}{l}\text { Socio-demographic } \\
\text { characteristics }\end{array}$} & \multicolumn{2}{|c|}{ Place of Delivery } & \multirow{2}{*}{ Total } & \multirow{2}{*}{$\mathrm{X}^{2}$} & \multirow{2}{*}{$\mathrm{P}$} \\
\hline & Home & Institutional & & & \\
\hline \multicolumn{6}{|c|}{ Age of women } \\
\hline $18-20$ & $2(2.1)$ & 92 (97.9) & 94 & \multirow{3}{*}{\multicolumn{2}{|c|}{1.74 .418}} \\
\hline $21-23$ & $19(5.2)$ & $\begin{array}{c}345 \\
(94.8)\end{array}$ & 364 & & \\
\hline 24 years & $8(5.4)$ & $\begin{array}{c}139 \\
(94.6)\end{array}$ & 147 & & \\
\hline \multicolumn{6}{|c|}{ Education of women } \\
\hline Illiterate & $6(18.8)$ & $26(81.2)$ & 32 & \multirow{4}{*}{\multicolumn{2}{|c|}{23.46 .000}} \\
\hline Primary education & $5(8.9)$ & 51 (91.1) & 56 & & \\
\hline Secondary education & 18 ( 3.9$)$ & $\begin{array}{c}449 \\
(96.1)\end{array}$ & 467 & & \\
\hline $\begin{array}{l}\text { Higher secondary } \\
\text { and above }\end{array}$ & - & $50(100.0)$ & 50 & & \\
\hline \multicolumn{6}{|c|}{ Occupation of women } \\
\hline Non-workers & $8(6.5)$ & 115 (93.5) & 123 & \multirow{3}{*}{\multicolumn{2}{|c|}{8.71 .013}} \\
\hline Agricultural labourers & $21(6.0)$ & 327 (94.0) & 348 & & \\
\hline $\begin{array}{c}\begin{array}{c}\text { Non-agricultural } \\
\text { labourers }\end{array} \\
\end{array}$ & - & $134(100.0)$ & 134 & & \\
\hline \multicolumn{6}{|c|}{ Standard of living index } \\
\hline Low & $17(7.3)$ & 217 (92.7) & 234 & \multirow{3}{*}{\multicolumn{2}{|c|}{21.35 .000}} \\
\hline Medium & $12(3.8)$ & 306 (96.2) & 318 & & \\
\hline High & - & $53(100.0)$ & 53 & & \\
\hline \multicolumn{6}{|c|}{ Age at marriage } \\
\hline Less than 18 years & $4(22.2)$ & $14(77.8)$ & 18 & \multirow{4}{*}{\multicolumn{2}{|c|}{15.54 .001}} \\
\hline 18-19 years & $17(5.5)$ & 290 (94.5) & 307 & & \\
\hline 20-21 years & $8(3.4)$ & 230 (96.6) & 238 & & \\
\hline $22-23$ years & - & $42(100.0)$ & 42 & & \\
\hline \multicolumn{6}{|c|}{ Birth order } \\
\hline First & $9(2.5)$ & 356 (97.5) & 365 & \multirow{3}{*}{\multicolumn{2}{|c|}{10.97 .004}} \\
\hline Second & $17(8.2)$ & 190 (91.8) & 207 & & \\
\hline Third & $3(9.1)$ & 30 (90.9) & 33 & & \\
\hline \multicolumn{6}{|c|}{ Exposure to mass media } \\
\hline More frequently & $4(1.6)$ & 248 (98.4) & 252 & \multirow{2}{*}{\multicolumn{2}{|c|}{12.73 .001}} \\
\hline Less frequently & $25(7.1)$ & 328 (92.9) & 353 & & \\
\hline \multicolumn{6}{|c|}{ Distance of health facility } \\
\hline Within $1 \mathrm{Km}$ & - & $78(100.0)$ & 78 & \multirow{3}{*}{\multicolumn{2}{|c|}{1.09 .581}} \\
\hline $2-3 \mathrm{Km}$ & $8(4.7)$ & 163 (95.3) & 171 & & \\
\hline 4 or more $\mathrm{Km}$ & $21(5.9)$ & 335 (94.1) & 356 & & \\
\hline Total & $29(4.8)$ & $576(95.2)$ & 605 & & \\
\hline
\end{tabular}

The (Table 4) shows the percentage distribution of SC women's place of delivery by their socio-demographic characteristics. The result shows that the younger women (18-20 age groups) were less likely than older women given birth at home. The women in the age group 18-20 were less likely to given birth at home $(2.1 \%)$ than those aged 21-22 (5.2\%). The relation between women's education and place of delivery was positively associated. All the women who had completed higher secondary and above level of education were preferred institutions for their delivery but at the same time home deliveries were more common (18.8\%) among illiterates $\left(X^{2}=23.46\right.$ and $\mathrm{p}=0.000)$. Delivery at the health facilities was quite common among women who were working in nonagricultural sector (100\%) than non-workers (93.5\%).

The proportion (Table 4) of women in households in the medium standard of living index (SLI) was less likely given birth at home (3.8\%) than women in low SLI (7.3\%) and also all the child deliveries among the women in households in the high SLI took place at institution. It discloses that the place of delivery was significantly associated with the women's SLI $\left(\mathrm{X}^{2}=21.35\right.$ and $\mathrm{p}=$ $0.000)$. It is also observed that the age at marriage and place of deliveries were positively associated. The women who married at later age (22 and above years) were less likely to given birth at home than those who married at an early ages. Birth order was significantly influence on the place of delivery among rural women. First birth order deliveries were less likely to happen at home (2.5\%) than higher birth order deliveries $(9.1 \%)\left(X^{2}=10.97\right.$ and $p=$ $0.004)$. The impact of mass media exposure of women on the place of delivery shows a strong positive association. The proportion of home deliveries was less among women who were more exposed to mass media $(1.6 \%)$ than less exposed women $(7.1 \%)$. All women who were residing within one $\mathrm{Km}$ preferred institutions for delivery whereas this proportion was $94.1 \%$ among women who residing four $\mathrm{Km}$ away from health centers. It shows that the proportion of home deliveries increased when the distance of health facilities increased.

\section{Discussion}

This study investigated that socio-demographic factor such as education, standard of living index, birth order and mass media have influence on women's choice of place of delivery in rural areas. Bivariate analysis indicates that all the women who had completed higher secondary education were preferred the health institution for their delivery. The proportion of home deliveries was higher among women in households in the less standard of living index. Mass media and birth order were significantly influence on the place of delivery among women in the study population.

This study has provided a snapshot insight into actual reasons of women for not delivering at institution. Around five percent of women were delivered at home in the study area. Majority of the home deliveries were monitored by traditional birth attendants (TBAs/Dais). The main reasons for not delivering at institution included: they had better care at home, TBAs/Dais were available, family members did not allow them, lack of transportation facility and lack of time to visit the health facility for delivery. Births 
delivered at home are usually more likely to be delivered without assistance from a health professional, whereas births delivered at health facilities are more likely to be delivered by health professional with at least minimal training in the provision of normal delivery services [19].

Traditional birth attendants (TBAs/Dais) have traditionally been assisting the women during child birth for centuries in India. TBAs provide community members with not only delivery services, but with emotional support and practical assistance both before and after the birth. TBAs are valued members of the community and can be more influential than outside medical personnel in encouraging community members to modify and improve existing practices surrounding pregnancy and childbirth [20]. In spite of the facts that a large proportion of the births in the country are being assisted by the TBAs particularly in the areas where higher order health care is not accessible and the fact that the TBAs are culturally acceptable, the country health programmes have abandoned them since last many years. If we look into the history, globally, the role of the TBA started to be taken seriously in the early 1950s when high maternal mortality rates become a concern in many developing countries. Several countries started training TBAs in clean and safe home delivery and some other health care-related roles [21].

Childbirth in a health facility while attended to by trained health professional has been shown to be associated with lower rates of maternal and neonatal mortality and morbidity compared to home births [22]. In poor settings, non- health facility deliveries are associated with increased maternal morbidity and mortality and increased newborn morbidity and mortality [23,24]. It is well recognized that women's current age plays an important role in the utilization of medical services. The result of the present analysis shows that the younger women (18-20 age groups) were less likely than older women given birth at home. Mothers' age may sometimes serve as a proxy for women's accumulated knowledge of health care services, which may have a positive influence on the use of health services. On the other hand, because of developments in modern medicine and improvements in educational opportunities for women in recent years, younger women might have an enhanced knowledge of modern health care services and place more value upon modern medicine [25,26,27]. Women's literacy is an important predictor for the use of maternal health care services $[23,27,28]$. It is well recognized that a woman's educational level has a positive impact on health care utilization. Increased education influences service use by increasing female decision-making power, increasing awareness of health services, changing marriage patterns, and creating shifts in household dynamics [23]. Evidence from the present study reveals that the women who had completed higher secondary and above level of education were preferred the health institutions for their delivery but at the same time home deliveries were more common among illiterates.

Socioeconomic factors such as income, household wealth, education, have been shown to be of greater importance in determining health service use than demographic factors [23,30]. Research consistently shows that a low income and the cost of services are important constraints on service utilization: increased income has a positive effect on the utilization of modern health care services and low income and the cost of services are important constraints on service utilization [26,30]. The present study shows that the proportion of women in households in the higher standard of living index was less likely given birth at home than women in low standard of living index. High birth order was found to be a predisposing factor of home delivery in India [31] as well as in four states of southern India; after an uneventful birth of the first child at home, subsequent deliveries are perceived to be low risk thus increasing the likelihood of delivering the subsequent babies at home [28,31].

Place of residence also plays an important predictor to prefer women's place of delivery. Living in urban areas increases the probability of pregnant women using trained professionals for birth deliveries [12,32]. The present study discloses that all women who were residing within one kilometer $(\mathrm{km})$ of radius preferred institution for delivery whereas this proportion was less among women who residing four $\mathrm{km}$ away from institutions. It shows that the proportion of home deliveries increased when the distance of health facilities increased. In southern India, urban residence increased the likelihood of institutional delivery compared to rural residence [28]. In addition to these, lower educational status, marital status and low standard of living index were factors found to be strongly associated with option of home delivery as against hospital delivery. Some studies in developing countries have shown that the decision to deliver at home is related to socio-demographic and economic factors such as income, educational status and marital status [33,34].

\section{Conclusion}

Socio-demographic factors have influence on women's choice of place of delivery in rural areas. Family tradition and poor socio-demographic condition of the family appear to be the main reasons for delivering at home. Majority of the home deliveries were monitored by traditional birth attendants (TBAs/Dais). The study findings show the importance of adopting a comprehensive approach to increase the availability and accessibility of maternal and child health care services in the community. Poverty alleviation strategies will contribute to improve access and utilization of maternal and child health care services. Strengthening the partnership program between village midwives and traditional birth attendants is recommended because of the frequent use of traditional birth attendants in this area. Training of traditional birth attendants would enable them to up-skill their delivery practice under the supervision of health professionals, especially in rural and remote areas. It also recommends that Government should be taken a comprehensive strategy to increase the availability, accessibility and affordability of delivery care services in rural areas. Public health strategies involving traditional birth attendants will be beneficial particularly rural/remote areas where their services are highly utilized.

\section{Conflict of Interests}

The authors declare no conflict of interest. 


\section{Acknowledgement}

We thank Annamalai University, Tamilnadu, India, Institutional Ethics Committee and the Dean, who permitted us to conduct the study. We also thank the respondents for their priceless information.

\section{References}

[1] Imogie AO, Agwubike EO, Aluko K. Assessing the role of traditional birth attendants (TBAs) in health care delivery in Edo State, Nigeria. African Journal of Reproductive Health 2002; 6: 94-100.

[2] World Health Organization (WHO), Maternal mortality, Millennium Development Goal (MDG) 5. 2013; 1.

[3] Gabrysch S, Campbell O. Still too far to walk: literature review of the determinants of delivery service use. BMC Pregnancy Childbirth 2009; 9 (34).

[4] Stephenson R, Baschieri A, Clements S, Hennink M, Madise N. Contextual influences on the use of health facilities for childbirth in Africa. American Journal of Public Health 2006; 96 (1): 84-93.

[5] Say L, Raine R. A systematic review of inequalities in the use of maternal health care in developing countries: examining the scale of the problem and the importance of context. Bull WHO. 2007; 85: 812-819.

[6] Gabrysch S, Cousens S, Cox J, Campbell O. Distance and quality of care strongly influence choice of delivery place in rural Zambia: A study linking national data in a Geographic Information System. Journal of Epidemiology and Community Health 2011; 65: A42A42.

[7] Thind A, Mohani A, Banerjee K, Hagigi F. Where to deliver? Analysis of choice of delivery location from a national survey in India. BMC Public Health 2008; 8: 29.

[8] Mills S, Bertrand JT. Use of health professionals for obstetric care in northern Ghana. Studies in Family Planning 2005; 36 (1): 45-56.

[9] Borghi J, Ensor T, Neupane BD, Tiwari S. Financial implications of skilled attendance at delivery in Nepal. Tropical Medicine and International Health 2006; 11 (2): 228-237.

[10] Liu M, Zhang Q, Lu M, Kwon CS, Quan H. Rural and urban disparity in health services utilization in China. Medical Care 2007; 45 (8): 767-774.

[11] Adanu R. The challenge of meeting the Millennium Development Goal for maternal health. International Journal of Gynaecology and Obstetrics 2008; 102: 1-2.

[12] Letamo G, Rakgoasi SD. Factors associated with the non-use of maternal health services in Botswana. Journal of Health and Population Nutrition 2003; 21: 40-47.

[13] Gage AJ, Callixte MG. Effects of physical accessibility of maternal health services on their use in rural Haiti. Population Studies (Cambridge) 2006; 60: 271-88.

[14] Wilson SB, Collison AHK, Richardsom S. The maternity Ghan experience. International Journal of Gynecology and Obstetrics 1997; 59 (2): S1650-S172.

[15] Carr D. Improving the health of the world's poorest people. Health Bulletin 2004; 3-12.
[16] Samai O, Sengeh P. Facilitating emergency care through transportation and communication, Bo, Sierra Leone. International Journal of Gynecology and Obstetrics 1997; 59(2): S157- S164.

[17] Census, Govt of India (Office of the Registrar General and Census Commissioner). 2001.

[18] Ministry of Health and Family Welfare (MOHFW), Reproductive and Child Health Programme: Schemes for Implementation, Department of Family Welfare, New Delhi. 1997.

[19] Ministry of Health (MOH). Nepal Demographic and Health Survey 2001. Kathmandu, Nepal: MOHP, New Era and ORC Macro, qsw Calverton, Maryland. 2002.

[20] Ebrahim GJ. Cross-cultural aspects of pregnancy and breast feeding. Nutritional Sociology 1980; 39: 13-15.

[21] Dadhich JP. The Traditional Birth Attendants- Can we do without them? Journal of Neonatology 2009: 23:3.

[22] Levin A, McEuen M, Dymatraczenko T, Sengooba F, Mangani R, Van Dyck G. Costs of Maternal Health care Services in three Anglophone African Countries. International Journal of Health Planning and Management 2003; 18 (1): 3-22.

[23] Stephenson R, Baschieri A, Clements S, Hennink M, Madise N. Contextual influences on the use of health facilities for childbirth in Africa. American Journal of Public Health 2006; 96: 84-93.

[24] Tuladhar H, Dali SM, Pradhanang V. Complications of home delivery: a retrospective analysis. Journal of Nepal Medical Association 2005; 44: 87-91.

[25] Mpembeni RNM, Killewo JZ, Leshabari MT, Massawe SN, Jahn A, Mushi D. Use pattern of maternal health services and determinants of skilled care during delivery in Southern Tanzania: implications for achievement of MDG-5 targets. BMC Pregnancy Childbirth 2007; 7: 29.

[26] Stanton C, Blanc AK, Croft T, Choi Y. Skilled care at birth in the developing world: Progress to date and strategies for expanding coverage. Journal of Biosocial Sciences 2007; 39: 109-120.

[27] Chakraborty N, Islam MA, Chowdhury RI, Bari W, Akhter HH. Determinants of the use of maternal health services in rural Bangladesh. Journal of Health Promotion 2003; 18: 327-37.

[28] Navaneetham K, Dharmalingamb A. Utilization of maternal health care services in Southern India. Social Science Medicine 2002; 55: 1849-1869.

[29] Mayhew M, Hansen PM, Peters DH, Edward A, Singh LP, Dwivedi V. Determinants of skilled birth attendance in Afghanistan: a Cross-sectional study. American Journal of Public Health 2008; 98: 1849-56.

[30] Houweling TAJ, Ronsmans C, Campbell OMR, Kunst AE. Huge poor-rich inequalities in maternity care: an international comparative study of maternity and child care in developing countries. Bull World Health Organ 2007; 85: 745-754.

[31] Thind A, Mohani A, Banerjee K, Hagigi F. Where to deliver? Analysis of choice of delivery location from a national survey in India. BMC Public Health 2008; 8: 29.

[32] Celik Y, Hotchkiss DR. The socio-economic determinants of maternal health care utilization in Turkey. Social Science Medicine 2000; 50: 1797-806.

[33] Katung PY. Socio-economic factors responsible for poor utilization of primary health care services in a rural community in Nigeria. Nigerian Journal of Medicine 2001; 10: 20-59.

[34] Satoko Y, Sophal O, Susumu W. Determinants of skilled birth attendance in rural Cambodia. Tropical Medicine International Health 2006; 2: 238-251. 